\title{
The Use of Data from Sampling for Bacteriology for Genetic Selection Against Clinical Mastitis
}

\author{
W. Ouweltjes, ${ }^{* 1}$ J. J. Windig, ${ }^{*}$ G. de Jong,† T. J. G. M. Lam,‡ J. ten Napel, ${ }^{*}$ and Y. de Haas \\ *Animal Sciences Group, PO Box 65, NL-8200 AB Lelystad, the Netherlands \\ †NRS, Animal Evaluation Unit, PO Box 454, NL-6800 AL Arnhem, the Netherlands \\ fDutch Udder Health Center at GD Animal Health Service Ltd., PO Box 9, NL-7400 AA Deventer, the Netherlands
}

\begin{abstract}
One breeding objective of Dutch cattle breeders is to improve genetic resistance against clinical and subclinical mastitis. Because of a lack of direct mastitis information, udder health breeding values are based on indirect traits. Inclusion of direct information on clinical mastitis could improve reliability of breeding values. The aim of this study was to investigate whether data from milk samples sent in for bacteriology are potential sources of information for the occurrence of mastitis, which may be used in animal breeding, and if so how this data can be used. Although there are 2 separate flows of milk samples for bacteriology in the Netherlands, it was not considered necessary to account for the origin of the samples. In both flows, the majority of the samples are visually normal and flow-specific traits are highly correlated. Therefore, information from these flows is combined for genetic analysis. Nearly two-thirds of the bacteriology data could be linked to milk recording and pedigree records. Relatively few farmers $(<3 \%)$ took 5 or more samples for bacteriology between January 1, 2003, and March 31, 2006. Their herds had, on average, greater milk production and lower cell counts than herds for which no samples were taken. However, the range and variation within both groups of herds for these variables was similar and there was a large overlap in sires used within both groups. Whether or not samples were taken for bacteriology turned out to be a potentially useful indicator for clinical mastitis at the cow level, because this trait had a strong positive genetic correlation with clinical mastitis registered by farmers (0.84 or 0.89 , depending on the data set) and similar heritability $(2 \%)$ and genetic variation. Also, genetic correlations of bacteriology with SCC traits were similar to those for farmer-registered clinical mastitis. An important advantage of these bacteriology data is that they are already collected routinely and
\end{abstract}

Received May 13, 2008.

Accepted August 26, 2008.

${ }^{1}$ Corresponding author: Wijbrand.Ouweltjes@wur.nl stored in a central database in the Netherlands; this is not the case for registration of clinical cases. Thus, data from bacteriological culturing can be used for genetic improvement of udder health.

Key words: somatic cell count, clinical mastitis, bacteriological sampling, genetic selection

\section{INTRODUCTION}

In milk recording schemes, SCC is determined at the cow level. These data are a valuable component of udder health monitoring programs (Schukken et al., 2003) and are also useful for breeding. However, because mastitis takes place at quarter level, increases in SCC during inflammations are generally less pronounced at cow level than at quarter level (Djabri et al., 2002; Schukken et al., 2003). Bacteriological culturing of quarter milk samples, which can indicate whether quarters are infected and by which pathogens, is a widely accepted additional tool for management support (NMC, 2008). The culture outcomes are used to determine curative strategies, for herd level problem diagnosis and for finetuning prevention plans. Bacteriological culturing could generate a continuous flow of udder-health-related data that provides additional information to improve reliability of udder health breeding values. Up to now, information from these samples has not been used for genetic evaluation, despite the fact that breeding is an important tool to improve udder health in the longterm (Heringstad et al., 2000).

The Dutch breeding goal for udder health is to decrease genetic susceptibility to clinical mastitis (CM) and subclinical mastitis (SCM; De Haas et al., 2008), where SCM is defined by Van den Borne et al. (2006). Both aspects are weighted equally. In most countries, including the Netherlands, there is no routine data collection of information on CM itself in a national database. Therefore, Dutch udder health breeding values are currently purely based on indirect information: SCC, milking speed and udder and teat conformation traits (De Jong and Lansbergen, 1996; NRS, 2005). Several studies have shown that direct information on $\mathrm{CM}$ can 
be useful to improve the reliability of breeding values for udder health (Heringstad et al., 2000; Mark et al., 2002). Another benefit of having direct CM information is that genetic correlations to be used between index traits and breeding goal can be estimated.

Currently in the Netherlands, GD Animal Health Service (GD) cultures approximately 1,000 quarter milk samples per week from 2 different sample flows (outlined in Materials and Methods). These flows are designed for CM and SCM samples, respectively. Thus, the 2 sample flows may represent these different aspects of udder health. This could imply that the information from the flows cannot be combined but should be treated separately. It was assumed that impaired udder health was the main reason to submit samples for bacteriological culturing, although some other minor reasons for bacteriological culturing, such as research projects or animal sales, can be supposed. All results are stored in a central database at GD and are thus potentially available for the national breeding value estimation. However, this requires that these data can be linked with data from the national database used for genetic evaluations.

Although only a fraction $(<3 \%)$ of Dutch dairy farmers regularly submit samples, all farms experience mastitis. It is not clear to what extent farms that do submit samples for bacteriology are comparable for mastitis to those that do not. Bacteriology data are potentially useful for udder health breeding value estimation if one or more traits can be derived from these data that are heritable, have large genetic variation, and have moderate to strong genetic correlations with the breeding goal [which is to decrease genetic susceptibility to CM and SCM (De Haas et al., 2008)]. Genetic parameters and correlations of traits derived from bacteriological culturing data with CM and SCM traits as defined in the data sets described by De Haas et al. (2008) can give an indication of the added value of these data for breeding purposes.

The overall objective of this study was to investigate whether data from bacteriological culturing of quarter milk samples provide a useful source of information on $\mathrm{CM}$ for udder health breeding value estimation. The specific objectives were: 1) to investigate whether the information of the 2 sample flows can be combined and how traits derived from these data have to be defined; 2) to compare the farms submitting samples to farms not submitting samples; 3) to estimate heritability of bacteriology traits and genetic correlations with other udder health traits in the same data set; and 4) to estimate genetic correlations of bacteriology traits with clinical and subclinical mastitis traits used in other data sets

\section{MATERIALS AND METHODS}

\section{Available Bacteriology Data}

From the GD database 527,074 records of quarter milk samples were extracted from 13,309 farms. The data set contained all samples that arrived at the laboratory for bacteriology between June 17, 1999, and March 31, 2006; $90.9 \%$ of the records had a unique cow identification. Records that were not unique regarding the combination of herd, cow identification, laboratory entry date, and quarter $(0.58 \%$ of the records with cow identification) were excluded. On average, 2.5 samples were submitted per cow per sampling date. For 19,011 animals out of 158,771 more than one sample date was recorded, with a maximum of 17 sample dates.

\section{Bacteriological Sampling in the Netherlands}

In the Netherlands, 2 distinct flows of bacteriology samples, both developed to support udder health management on commercial farms, can be distinguished. The first is the high SCC sample flow (program flow): GD operates an udder health improvement program where farmers are encouraged to take quarter milk samples for bacteriology and determination of SCC of cows with high composite SCC at the most recent milk recording, but no CM symptoms. Farmers that participate in this program are expected to sample all quarters of a cow. The laboratory costs per sample are reduced compared with standard prices. In the program flow, high-SCC cows detected at the regular milk recording are sampled with the purpose of detecting both the infected quarter and the pathogens responsible for SCM. The second flow consists of all samples not taken as part of the high SCC program (ad hoc flow). This flow is meant for individual quarter samples with the purpose of detecting CM.

The milk samples for both flows are processed according to international standards (Hogan et al., 1999). The treatment and analysis of the samples is similar for both flows, but there are some logistic differences. Samples from the ad hoc flow are sent in via veterinary practices, whereas the program flow samples are sent in together with samples from the regular milk recording. After arriving at GD, all samples are scored for visual appearance (color and presence or absence of clots) by an experienced technician to identify abnormal samples. Samples that are classified as visibly abnormal are excluded for SCC determination. In all other samples, SCC is determined by the same laboratory that analyzes the regular milk recording samples with a Fossomatic cell counter (Foss Electric, Hillerød, Denmark). For both flows, all samples are cultured for bacteriology, but for 
the ad hoc flow, cultures are analyzed in more detail. The results of samples from both flows are recognizably stored in the database of GD, and $47 \%$ of all records in the available data were from the program flow. The majority of the 13,309 farms, however, only submitted samples through the ad hoc flow, while 1,513 farms submitted samples through both the ad hoc flow and the program flow.

To include information from bacteriological culturing in genetic analyses it was required that one or more relevant traits were derived from these data. Our a priori expectation was that the program flow samples mainly represented subclinical cases and the ad hoc flow mainly represented clinical cases. In that situation, it would not be possible to combine the information from both sample flows in one trait, but they would have to be treated separately. To evaluate this, the distribution of records over quarters, the percentages of abnormal samples, the number of samples per cow per sample date, and the distribution of quarter SCC were compared for both flows. Furthermore, genetic correlations between flows were estimated.

\section{Farm Level Selection of Bacteriology Data for Genetic Analysis}

To be useful for genetic evaluations, the cow identification in the bacteriology data was matched with the national database used for genetic evaluations. For reliable pedigree information, a further requirement was that the cows were herdbook-registered. This was the case for $63.6 \%$ of the bacteriology records. These records were from 93,313 cows in 8,496 farms. Because most of the farmers submitted only a few samples, only records from farms that submitted samples at least 5 times between January 1, 2003, and March 31, 2006, were retained. There were 477 farms (sampling farms) that fulfilled this criterion, with 49,900 bacteriology records from 12,379 cows. To obtain an inference on how representative these farms were compared with all Dutch farms, 500 farms (control farms) that did not submit any sample for bacteriological culturing were randomly chosen from the national milk recording database.

\section{Combination with Production and Pedigree Data}

For all 977 farms, all milk recording data for the period between January 1, 2003, and March 31, 2006, and pedigree information from all herdbook-registered cows was extracted from the national database. The production file contained 1,950,298 test-day records of 248,904 lactations. The pedigree file contained the ancestry of 387,909 animals $(359,546$ cows and 28,363 bulls) back to 1908. Milk recording data from the sampling farms were compared with those from the control farms to determine to what extent sampling farms are comparable to all Dutch farms with respect to milk production and SCC. For this comparison, farms with all test-day averages based on less than 10 sampled cows were excluded. In such cases, it was expected that only part of the herd was herdbook-registered. Thus, data from 450 sampling farms and 494 control farms were compared.

\section{Further Data Selection and Edits}

From the original phenotypic records, 2 data sets for genetic analysis were constructed, one with data from both control farms and sampling farms (all farms) and one with data from sampling farms only. Farms with an average of less than 25 cows sampled for milk recording per test day, farms with the first test day after March 1 , 2003 , and farms with the last test day before February 1, 2006, were excluded. In total, 404 sampling farms and 391 control farms fulfilled these requirements. Lactations were included when parity was 1,2 , or 3 and calving date was November 28, 2001 (400 d before January 1, 2003) or later. Further requirements were at least $75 \%$ of Holstein Friesian genes and calving age of at least $640 \mathrm{~d}$.

For the analyses, a pedigree file was constructed based on sires and maternal grandsires (MGS). For the all farms data set, records were excluded for sires with less than 10 offspring (as daughters or granddaughters) in the remaining data. This data set consisted of 127,050 lactation records from 72,221 cows in 795 farms. These cows were daughters of 2,956 sires and granddaughters of 2,918 maternal grandsires, of which 2,290 also appeared as sire. The pedigree file based on sires and maternal grandsires contained 5,972 records.

For the sampling farms data set, records were excluded for sires with less than 5 offspring (as daughters or granddaughters) in the remaining data. This data set consisted of 70,216 lactation records from 39,769 cows in 404 farms. These cows were daughters of 2,523 sires and granddaughters of 2,633 maternal grandsires, of which 1,790 also appeared as sire. The pedigree file for this data set contained 5,515 records.

In addition to the data sets described above, 2 data sets (A and B) described previously by De Haas et al. (2008) were used for analyses. Apart from bacteriology data, these data sets held similar information to the bacteriology data set, but also contained information on recorded CM cases. For data set A, cases of CM were recorded by milk recording personnel, and for data set $\mathrm{B}, \mathrm{CM}$ was recorded by farmers in management information systems. For both data sets, CM records contained both cow ID and date, enabling us to match 
Table 1. Number of common sires between sampling farms data set and data sets A and B of De Haas et al. $(2008)^{1}$

\begin{tabular}{lccc}
\hline Data set & A & B & $\begin{array}{c}\text { Sampling } \\
\text { farms }\end{array}$ \\
\hline A (De Haas et al., 2008) & 1,903 & & \\
B (De Haas et al., 2008) & 1,178 & 3,126 & \\
Sampling farms & 1,242 & 1,838 & 3,366 \\
\hline
\end{tabular}

${ }^{1}$ Number of sires with progeny per data set on diagonal, numbers off diagonals represent number of sires appearing in both data sets.

these records to lactations. For these data sets, similar edits were applied as for the data sets described above. Data set A consisted of 28,688 lactation records from 21,673 cows in 394 herds. The cows were daughters of 1,422 sires and granddaughters of 1,268 maternal grandsires, of which 787 also appeared as sire. Data set B consisted of 56,726 lactation records from 30,145 cows in 272 herds. These cows were daughters of 2,446 sires and granddaughters of 2,471 maternal grandsires, of which 1,791 also appeared as sire.

The data from sampling farms and data sets $\mathrm{A}$ and $\mathrm{B}$ were combined for analysis. Estimation of genetic correlations between mastitis traits in these 3 data sets was possible due to overlap in sires with progeny (Table $1)$.

\section{Trait Definitions}

Based on results of the data inventory, one binary trait was derived from the culturing data for genetic analysis of the bacteriology data sets. This trait was called "culture sampling" (CS). For those farms that submitted samples, a value of 1 was assigned for CS for lactations with at least 1 sample taken and submitted for bacteriological culturing between $15 \mathrm{~d}$ before calving and $400 \mathrm{~d}$ after calving. For the other lactations on these farms, a value of 0 was assigned. The last $15 \mathrm{~d}$ before calving were included to correctly assign sampling dates to lactations, but sampling before calving rarely occurred. For lactations on farms that did not submit samples, the value "missing" was assigned to this trait. Separate CS traits for the 2 flow schemes were also investigated to estimate genetic correlations with the composite CS trait. The CS trait was regarded as a potential indicator of either CM or SCM, based on the assumption that udder health problems triggered the farmer to submit samples. For data sets A and B, $\mathrm{CM}$ was defined as a binary trait on lactation level similar to CS for the bacteriology data sets. Calving dates and lactation lengths for trait definitions were obtained from the milk production files. Furthermore, indicators of SCM (ISCM) were derived from test-day SCC for all data sets, and defined as a transition from
2 consecutive SCC-recordings below a certain threshold to one SCC recording above that threshold (Van den Borne et al., 2006). The thresholds used in this study were the same as those used in the Dutch national milk recording: 150,000 cells $/ \mathrm{mL}$ for primiparous cows, and 250,000 cells/mL for multiparous cows (De Haas et al., 2008). In addition to these udder health traits, 3 sets of alternative SCC traits were defined. Test-day SCC records from d 5 to 400 of lactation were used to construct these traits. The first set consisted of SCC averaged over different lengths of lactation. The second set was derived from SCC records exceeding certain thresholds. The third set corresponded to patterns of peaks in SCC, where a test day with high SCC preceded and followed by test days with low SCC is defined as an environmental peak, and a test day with low SCC followed by 2 test days with high SCC is defined as a contagious peak (De Haas et al., 2003). These traits are further described in De Haas et al. (2008) and are summarized in Table 2. Mean values for CS in the bacteriology data sets $(8.7 \%)$ were comparable to those for CM in data sets A and B of De Haas et al. (2008;10.9 and $10.4 \%$, respectively).

\section{Statistical Analyses}

Genetic parameters were estimated for udder health traits, both for the all farms data set and the sampling farms data set. (Co)variance components were estimated with a generalized linear mixed model using ASReml (Gilmour et al., 2006). Cows with missing values for ISCM or SCC-traits were included in the analyses. The model included random effects for sire and MGS and for cow, the latter to account for permanent animal effects (PERM) across repeated lactations. The model used was:

$$
\begin{gathered}
\mathrm{Y}=\mu+\text { fixed effects }+\mathrm{S}_{\text {sire }}+1 / 2 \mathrm{~S}_{\mathrm{mgs}} \\
+\mathrm{PERM}_{\mathrm{cow}}+\mathrm{e} .
\end{gathered}
$$

The random sire effect was identified by the subscripts for sire and MGS; $S_{\text {sire }}$ and $S_{\text {mgs }}$, respectively. For each sire, only one effect (breeding value) was estimated. If a bull had entries in the data both as sire and as MGS, the breeding value as MGS was equal to half the breeding value as a sire (Calus et al., 2005). The sire effects were linked using the relationship matrix, and were assumed to be normally distributed with $\operatorname{var}\left(\mathrm{S}_{\text {sire or } \mathrm{mgs}}\right)=\sigma_{\mathrm{s}}{ }_{\mathrm{s}}$. Permanent animal effects contained environmental effects common to different lactations and genetic effects not covered by sire and MGS, such as a dam component, dominance, and Mendelian sampling terms. This 
effect was assumed to be normally distributed as well, with $\operatorname{var}\left(\mathrm{PERM}_{\text {cow }}\right)=\sigma_{\text {Ea }}^{2}$.

Fixed effects included were an interaction between herd and year of calving $(4,113$ classes in the data set of all farms, 2,121 classes in the data set of sampling farms, 1,174 classes in data set $\mathrm{A}$ and 1,647 classes in data set B), parity (with 3 classes: first, second, and third lactation), and month of calving (with 12 classes). A linear regression coefficient was included in the model for age at calving. Furthermore, linear regression coefficients were included in the model for days on trial (DOT) and days at start (DAS) for data set A and bacteriology data sets. These 2 variables were constructed to adjust for the fixed sampling periods for these data sets. For data set A DOT and DAS were calculated as described by De Haas et al. (2008). For bacteriology data sets, DOT was calculated by calculating the difference between (minimum of the last test date in a lactation, $400 \mathrm{~d}$ postpartum, and March 31, 2006) and (maximum of calving date and January 1, 2003). Days at start was determined by subtracting the calving date from January 1, 2003, and was zero for lactations starting after January 1, 2003.

Univariate analyses were carried out for CS, ISCM, and SCC-traits for both all farms and sampling farms data sets, using the model presented above. Bivariate analyses were carried out to estimate correlations between CS and ISCM and SCC-traits in both data sets, using the same linear model. Finally, genetic correlations of CS and ISCM in the sampling farms data set and $\mathrm{CM}$ and ISCM as defined in the data sets A and B described by De Haas et al. (2008) were estimated with bivariate analyses. Indicator of SCM was defined equally in all data sets and calculated from milk recording SCC. Therefore, for these analyses CS is regarded as a potential indicator trait for CM. Thus, the 3 data sets each had different indicators for CM: 1) a sample taken for bacteriology in the sampling farms data set, 2) farmer-diagnosed CM cases registered monthly at the herd tests in data set $\mathrm{A}$, and 3) CM cases registered in farm management information systems in data set B. In all 3 data sets, CM was a binary trait. For these analyses, the same model was used as for the analysis of the separate data sets. In the combined data set, 5,084 different sires were represented as sire and/or maternal grandsire and 4,785 different classes of herd $\times$ year of calving were represented. Genetic parameters were calculated from the estimated variance components. The additive genetic variance was calculated by multiplying the sire variance by 4 . The phenotypic variance $\left(\sigma_{p}^{2}\right)$ was the sum of the sire variance multiplied by 1.25 , plus the permanent animal and residual variance. The factor 1.25 is explained by the fact that effects for both sires $\left[(1)^{2}=1\right.$ times the sire variance $]$ and MGS $\left[(0.5)^{2}\right.$

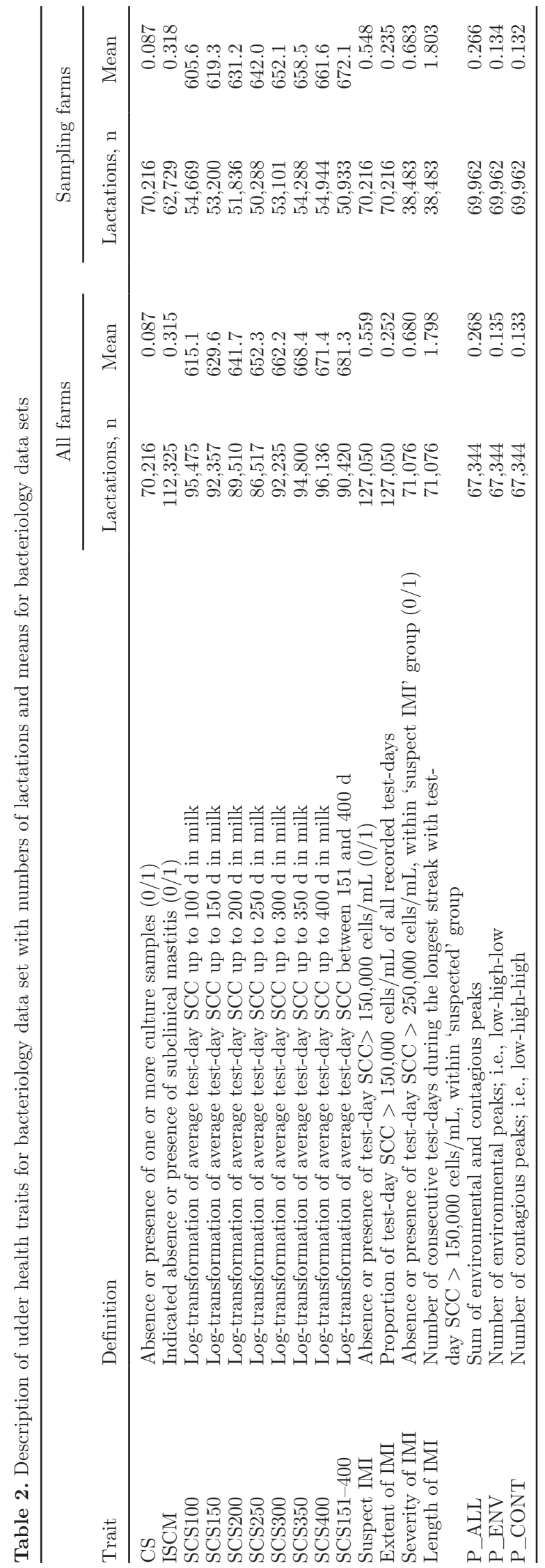


Table 3. Distribution of bacteriology records over quarters [left hind $(\mathrm{LH})$, left front $(\mathrm{LF})$, right hind $(\mathrm{RH})$ and right front $(\mathrm{RF})]$ and percentages of visually abnormal records ${ }^{1}$ thereof for program flow (n $=222,999)$ and ad hoc flow $(\mathrm{n}=248,160)$

\begin{tabular}{lccccc}
\hline & \multicolumn{2}{c}{ Program flow } & & \multicolumn{2}{c}{ Ad hoc flow } \\
\cline { 2 - 3 } \cline { 5 - 6 } Quarter & $\begin{array}{c}\text { \% of } \\
\text { records }\end{array}$ & $\begin{array}{c}\% \\
\text { abnormal }\end{array}$ & & $\begin{array}{c}\text { \% of } \\
\text { records }\end{array}$ & $\begin{array}{c}\% \\
\text { abnormal }\end{array}$ \\
\hline LH & 25.2 & 3.5 & & 22.0 & 11.1 \\
LF & 24.7 & 3.0 & & 20.3 & 9.2 \\
RH & 25.2 & 3.7 & & 22.2 & 11.3 \\
RF & 24.9 & 3.4 & & 20.7 & 9.8 \\
\hline
\end{tabular}

${ }^{1}$ Abnormal color or presence of clots observed by an experienced technician.

$=0.25$ times the sire variance] explained part of the total genetic variance (Calus et al., 2005). Heritabilities were calculated by dividing additive genetic variances by phenotypic variances. The permanent animal effect between lactations was calculated by dividing $\sigma_{\text {Ea }}^{2}$ by $\sigma^{2}$. Genetic, phenotypic, permanent animal, and error correlations were estimated using the corresponding variances and covariances.

\section{RESULTS}

\section{Phenotypic Comparison of Program Flow and Ad Hoc Flow}

The distribution of records over quarters and the percentage of records thereof classified as visually abnormal are given in Table 3. This table shows that for both sampling programs, hind quarters were sampled more often than front quarters. For the program flow nearly all samples had the quarter identified, while $15 \%$ of the ad hoc flow samples lacked quarter identification. Approximately 3\% of the program flow samples and $10 \%$ of the ad hoc samples had abnormal visual appearance.

For each cow and sampling date, 1 to 4 quarter samples could be taken, and thus potentially 0 to 4 samples could have abnormal visual appearance. The distribution of samples for both flows is presented in
Table 4. On average, more samples per cow per sampling date were taken for the program flow (3.45) than for the ad hoc flow (2.05). Although it was expected that for the program flow 4 samples would usually be taken per cow, in more than $20 \%$ of the cases 1,2 , or 3 samples were submitted. In $9.9 \%$ of the program flow samplings, one or more samples were considered visually abnormal. For the ad hoc flow, often only 1 sample per cow was submitted, whereas 4 samples were submitted in approximately $32 \%$ of these samplings. The percentage of ad hoc flow samplings with one or more visually abnormal records was higher than for the program flow records, but still relatively low (19.4\%). Additionally, the distribution of quarter SCC for both sample flows was described. The percentage of records per class of 1,000 cells $/ \mathrm{mL}$ for SCC below $1 \times 10^{6}$ is presented in Figure 1. For the program flow, $16.2 \%$ of the samples had an SCC greater than 1,000,000 cells/ $\mathrm{mL}$; for the ad hoc flow, $25.8 \%$ of the samples had an SCC greater than 1,000,000 cells/mL.

\section{Comparison of Sampling Farms and Control Farms}

Figures on milk production data from the sampling farms and the control farms are presented in Table 5. This table indicates that sampling farms had similar herd size to control farms $(P=0.920)$, but had greater average production, lower SCC, and a shorter test-day interval $(P<0.001)$. The range for production and SCC was, however, similar for both groups of farms although not statistically tested. Fat and protein percentages were similar, although the mean fat percentage of the 2 groups of farms was significantly different $(P=0.04)$.

Averages for the analyzed traits for all farms and for the sampling farms are presented in Table 2. For sampling farms, on average $8.7 \%$ of lactations had at least one sample submitted for bacteriology. Variation between farms in percentages of lactations with one or more samples was large, as 12 farms had submitted samples for less than $1 \%$ of their lactations, whereas 7 had submitted samples for more than $25 \%$ of their lactations. The differences in mean values for lactation

Table 4. Distribution of samplings (percentages of total number of samplings, for program flow ( $\mathrm{n}=64,579$ ) and ad hoc flow $(\mathrm{n}=120,905))$

\begin{tabular}{lcccccc}
\hline & \multicolumn{2}{c}{ Program flow } & & \multicolumn{2}{c}{ Ad hoc flow } \\
\cline { 2 - 3 } \cline { 5 - 6 } $\begin{array}{l}\text { No. of records/cow/ } \\
\text { sample date }\end{array}$ & Normal & Abnormal $^{1}$ & & Normal & Abnormal $^{1}$ \\
\hline 1 & 11.1 & 3.8 & & 46.1 & 15.3 \\
2 & 2.8 & 0.6 & & 3.4 & 1.0 \\
3 & 3.0 & 0.3 & & 1.8 & 0.1 \\
4 & 73.2 & 5.2 & & 29.3 & 2.9 \\
\hline
\end{tabular}

${ }^{1}$ Abnormal $=$ sampling in which at least one quarter sample is classified as abnormal. 


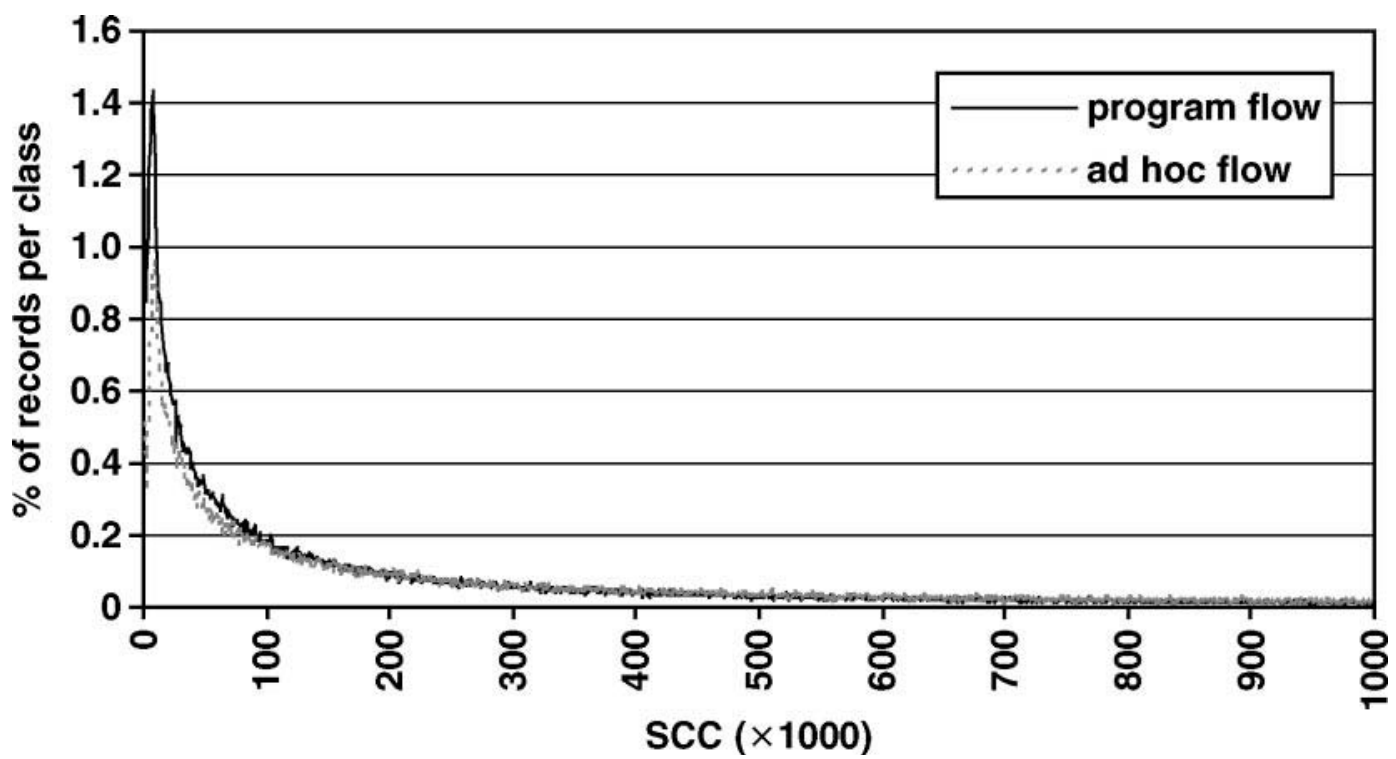

Figure 1. Distribution of SCC per class of 1,000 cells $/ \mathrm{mL}$ for bacteriology samples.

average SCC traits between the data sets reflect the greater SCC for the control herds. For all other SCC traits, mean values were very similar.

\section{CS per Flow Scheme and Composite CS}

Culture sampling traits defined for each flow scheme had lower heritabilities and genetic variation than the composite CS trait: $0.8 \%$ and 0.01 for ad hoc flow, $1.6 \%$ and 0.03 for program flow, and $2.0 \%$ and 0.04 for composite CS, respectively. When defining these traits, it was assumed that value was 1 when a sample in that particular flow was taken and 0 otherwise. However, this may not have been correct, because not all farms had samples in both flows. Because of the requirements when selecting data in the final data set for genetic analysis, nearly $80 \%$ of the bacteriology samples were from the program flow. Genetic correlation between CS from the 2 flow schemes was strong $(0.80 \pm 0.13)$ and both were highly correlated with the composite CS trait $(0.89 \pm 0.07$ and $0.99 \pm 0.01)$.

\section{Heritabilities for Bacteriology Data Sets}

The estimated heritabilities and genetic standard deviations of composite CS and ISCM for the sampling farms data set are presented in Table 6 . The estimates for the all farms data set were identical to those for the sampling farms data set, despite the greater mean values for lactation-average SCC traits for all farms. Therefore, only the estimates for the latter farms were presented. Heritabilities and genetic standard deviations for the other traits for both bacteriology data sets were similar to those reported by De Haas et al. (2008). The estimates of heritabilities from bivariate analyses were very similar to those of the univariate analyses.

\section{Genetic Correlations for Bacteriology Data Sets}

Genetic correlations of CS and ISCM with all other traits estimated for sampling farms and for all farms are presented in Table 7 . The estimates for both groups of farms were very similar, which can be partly ex-

Table 5. Herd statistics for sampling and control farms

\begin{tabular}{|c|c|c|c|c|c|c|c|c|}
\hline \multirow[b]{2}{*}{ Trait } & \multicolumn{4}{|c|}{ Sampling farms } & \multicolumn{4}{|c|}{ Control farms } \\
\hline & Mean & $\mathrm{SD}$ & Minimum & Maximum & Mean & $\mathrm{SD}$ & Minimum & Maximum \\
\hline No. of cows & $57.1^{\mathrm{a}}$ & 31.9 & 6 & 408 & $57.0^{\mathrm{a}}$ & 31.8 & 3 & 302 \\
\hline $\mathrm{kg}$ milk/cow & $27.0^{\mathrm{a}}$ & 3.8 & 9.7 & 45.7 & $25.1^{\mathrm{b}}$ & 3.9 & 7.4 & 40.3 \\
\hline Percentage of fat & $4.44^{\mathrm{a}}$ & 0.31 & 2.88 & 6.20 & $4.46^{\mathrm{b}}$ & 0.31 & 2.61 & 5.94 \\
\hline Percentage of protein & $3.52^{\mathrm{a}}$ & 0.13 & 2.81 & 4.68 & $3.52^{\mathrm{a}}$ & 0.14 & 2.90 & 4.36 \\
\hline Weighted SCC & $198^{\mathrm{a}}$ & 111 & 26 & 1,407 & $238^{\mathrm{b}}$ & 120 & 28 & 1,470 \\
\hline Test-day interval (d) & $30^{\mathrm{a}}$ & 7 & 1 & 161 & $34^{\mathrm{b}}$ & 8 & 1 & 150 \\
\hline
\end{tabular}


Table 6. Univariate estimates for heritabilities $\left(\mathrm{h}^{2} \pm \mathrm{SE}\right)$ and genetic standard deviation $\left(\sigma_{\mathrm{a}}\right)$ of culture sampling (CS) and indicator of subclinical mastitis (ISCM) for the sampling farm data set

\begin{tabular}{lcc}
\hline Trait & $\mathrm{h}^{2}$ & $\sigma_{\mathrm{a}}$ \\
\hline CS & $0.02 \pm 0.004$ & 0.039 \\
ISCM & $0.03 \pm 0.005$ & 0.073 \\
\hline
\end{tabular}

plained by the fact that $53 \%$ of the records in the all farms data set were from sampling farms. In general, CS had strong genetic correlations with the other udder health traits, but was genetically different from ISCM. Genetic correlations with lactation-average SCC traits did not increase with lactation length for CS. However, they did increase with increasing lactation length for ISCM. For most alternative SCC-traits, genetic correlations with CS were stronger than those with ISCM.

\section{Bivariate Analyses Between Data Sets}

Results for the combined analyses of CM/CS and ISCM in the sampling farms data set and the 2 data sets described in De Haas et al. (2008) are presented in Table 8. Although mastitis indicators CS and CM were defined differently in all 3 data sets, these traits are highly correlated but seem not to be genetically identical. The definition of ISCM was the same in all data sets and the results indicate that the correlations are nearly unity. During the iteration process, correlations for 2 of the 3 combinations were fixed at 1.00 by ASReml. For these combinations a correlation of 0.99 is presented. Correlations between $\mathrm{CM}$ and SCM in different data sets vary between 0.5 and 0.7 .

\section{DISCUSSION}

The main objective of this study was to investigate the use of data from bacteriological culturing of quarter milk samples as a source of information for estimation of udder health breeding values. The results indicated that the absence (0) or presence (1) of milk samples submitted for bacteriological testing in a lactation (CS) was potentially useful as an indicator of CM and genetically differed from ISCM. This is remarkable, because the majority of the bacteriology data used in the genetic analysis was from the program flow. This flow was designed for cows with high SCC but without signs of CM. Therefore, it is to be expected that CM will not have occurred in all cases in which samples were taken. Moreover, it can be assumed that for the most severe cases of CM, no bacteriology samples were submitted because treatment was started immediately. Therefore, phenotypically CS will not be a good indicator for CM at cow level.

Pathogen information was available for all samples submitted. In itself, this type of data can be useful for breeding programs because it supplies more specific information than disease incidence only (Koivula et al., 2007). However, we did not use the culture results to refine the trait definition of CS, the reasons being: 1) no samples were submitted for $91.3 \%$ of all lactations, 2) $2.4 \%$ had only negative cultures, 3) $2.9 \%$ revealed minor pathogens, and 4) $3.4 \%$ revealed major pathogens. Preliminary analysis with traits defined based on the outcome of the bacteriological test, distinguishing between samples with negative cultures and samples with minor or major pathogens, revealed that these traits had very low heritabilities $(<0.01)$ and little ge-

Table 7. Bivariate estimates of genetic correlations $( \pm \mathrm{SE})$ between culture sampling $(\mathrm{CS})$ and indicator of subclinical mastitis (ISCM) and SCC traits ${ }^{1}$ for bacteriology data sets

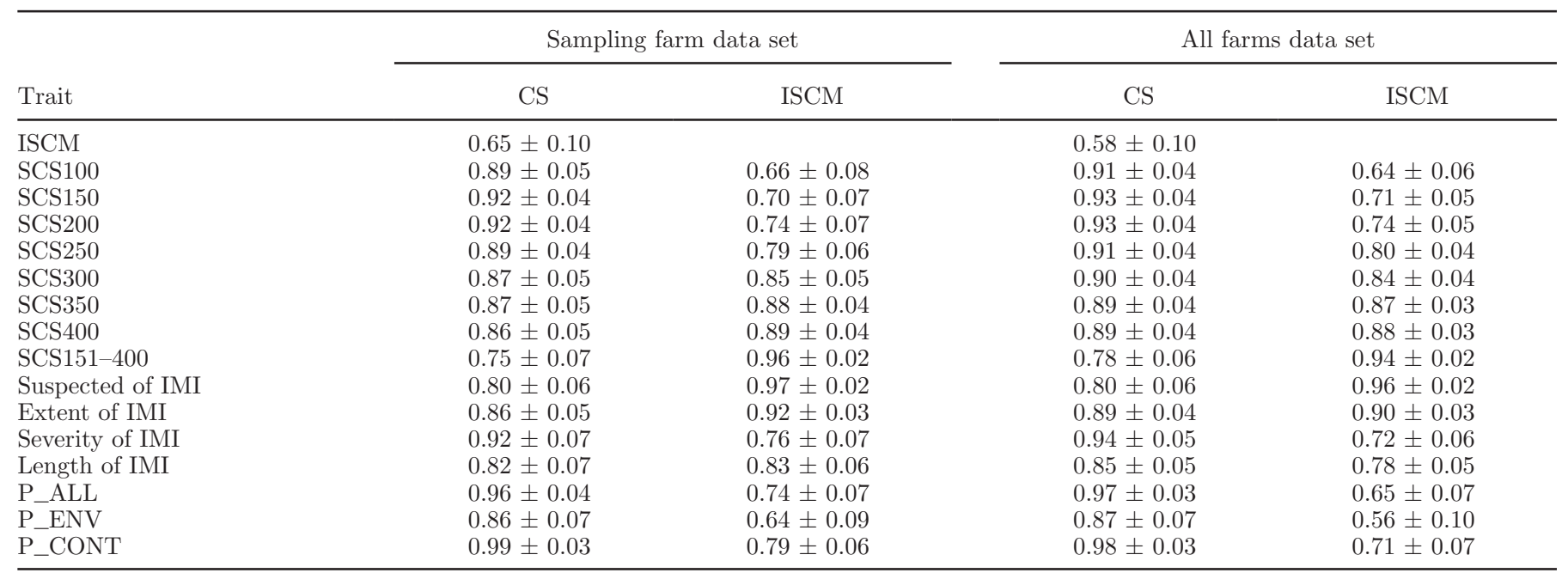

${ }^{1}$ See Table 2 for abbreviation and definition of the traits. 
Table 8. Bivariate estimates of genetic correlations ( $\pm \mathrm{SE}$ ) between clinical mastitis $(\mathrm{CM})$ and indicator of subclinical mastitis (ISCM) in data sets A and B of De Haas et al. (2008) and culture sampling (CS) ISCM for the sampling farm data set

\begin{tabular}{lcccc}
\hline & CM data set A & CM data set B & ISCM data set A & ISCM data set B \\
\hline CM data set B & $0.86 \pm 0.09$ & & $0.56 \pm 0.13$ & \\
CS (sampling farms) & $0.89 \pm 0.08$ & $0.84 \pm 0.08$ & $0.74 \pm 0.10$ & $0.61 \pm 0.11$ \\
ISCM data set B & $0.51 \pm 0.14$ & & $0.99^{1}$ & \\
ISCM (sampling farms) & $0.70 \pm 0.12$ & $0.49 \pm 0.11$ & $0.96 \pm 0.04$ & $0.99^{1}$ \\
\hline
\end{tabular}

${ }^{1}$ Correlations fixed at 1.00 .

netic variation, probably caused by the abundance of missing values for these traits. The advantage of CS as mastitis-trait instead of pathogen-specific traits is that "no sample" can be considered as a negative result instead of a missing value, whereas for pathogen-specific traits "no sample" must be distinguished from true negative samples. Even when pathogen-specific mastitis traits are not included in the selection index, these traits could be included in the breeding goal. Compared with $\mathrm{CM}$, this has the disadvantage that improvement in one area may coincide with impairment in another (Schukken et al., 1997). It was not feasible to estimate reliable genetic correlations of pathogen-specific traits with other udder health traits because the proportion of lactations with bacteriology data was insufficient. Therefore, the Dutch breeding goal only includes CM and SCM in general, and it does not include pathogenspecific traits in the selection index.

Although no pathogens were found for $28 \%$ of the sampled lactations, it does not necessarily indicate that all quarters were healthy. For instance, Sol et al. (2002) found negative culture results for subclinically infected cows, Olde Riekerink et al. (2008) reported negative culture samples from cows with CM and Sears et al. (1990) reported negative cultures for cows infected with Staphylococcus aureus. These authors stated that this was due to a cyclical shedding pattern of $S$. aureus. Another explanation for negative cultures is that cows were also sampled which had successfully eliminated an infection but had not yet returned to preinfection SCC levels (Van Werven et al., 1997). Koivula et al. (2007) reported similar percentages of negative culture samples as found in this study for both clinical and subclinical cases. Therefore, negative cultures should not be regarded as false positive indicators for CM. It should be noted that CS is not a perfect indicator of true CM. CS could give biased estimates of true CM if farmers are more likely to sample high-producing cows than low-producing cows. It is to be expected, however, that farmers are also more likely to cull low-producing cows when they have mastitis. When these cows are not treated, their CM cases might also not be recorded. Culture sampling as an indicator of $\mathrm{CM}$ at cow level will have false negatives for severe clinical cases and may have false positives when sampling is triggered by high bulk milk SCC. Both false negatives and false positives lower the correlation between $\mathrm{CS}$ and $\mathrm{CM}$; therefore, a correlation of 1 between these traits is not to be expected. Despite this, the genetic correlation estimated between CS and CM is high. This suggests that the assumption that sampling indicates udder health problems is realistic for genetic analysis.

\section{Comparison of Sample Flows}

In the ad hoc flow, $15 \%$ of the quarters lacked quarter identification, whereas this rarely occurred in the program flow. The ad hoc flow often contained only one sample per cow, so the farmer did not need quarter identification to interpret the results. Beforehand, it was expected that the program flow samples would represent SCM and the ad hoc flow would represent CM. This would have enabled us to distinguish between clinical and subclinical cases by defining a CS trait for each sample flow separately. However, the majority of samples from both flows consisted of visually normal milk and the distribution of SCC was similar. Culture sampling traits defined separately for the 2 sample flows had a strong genetic correlation (0.80). It was not possible to account for sample flow as a fixed effect in the model, because for the majority of the lactations no samples were taken, and these lactations could not be assigned to either one of the flows because some farms were represented in both flows. Therefore, the 2 sample flows were combined in the rest of this study, and composite CS was used as a trait for genetic analysis. The logic behind the definition of composite CS is that the farmer presumably noticed something abnormal (either clinical signs or elevated cow SCC) which triggered the submission of samples.

\section{Comparison of Sampling Farms and Control Farms}

The number of farms that regularly took samples for bacteriology in the period studied was limited. For these farms, the averages for traits derived from SCC (Table 2) were similar to those reported by De Haas 
et al. (2008). Due to the fixed start and end dates in the data set, some lactations did not meet the criteria for number of test days required to calculate $\mathrm{SCC}$ averages. On average, as indicated by test-day SCC, herds that submitted samples for bacteriology did not have more udder health problems than the randomly selected control farms. Although milk production was significantly greater and SCC was significantly lower for sampling farms, Table 5 indicates that control farms had similar variation in herd statistics. The comparison of the genetic parameters for the data sets with and without the control herds (Table 7) revealed that these were similar too. Therefore, it was assumed that parameters for bacteriology farms could be used as overall population parameters.

Variation between farms in the percentage of lactations with bacteriology samples taken was large. This could reflect true differences in mastitis incidence between farms, but it is likely that it also reflects differences in the motivation of farmers to take samples. To study the effect of such management influences, an additional analysis was done with a data set of all farms. For sampling herds where less than $5 \%$ or more than $25 \%$ of the lactations were sampled, CS was considered to be missing for this analysis. For the lactations in all other farms, CS was defined as in previous analyses (0/1 or missing). Genetic correlations of this alternative CS trait with SCC traits were somewhat greater than those reported in Table 7, but showed a similar pattern. Genetic correlation of this alternative CS trait and ISCM was $0.64 \pm 0.09$. Therefore, we assume that differences between farmers in policy to submit samples for bacteriology have not significantly affected the estimated genetic parameters for CS in this study.

\section{Genetic Parameters for Bacteriology Data Sets}

In the analyses, CS and CM were modeled as linear traits, whereas these traits theoretically should be analyzed with logistic models. De Haas et al. (2008) reported similar estimates for genetic correlations from linear and logistic models. This agrees with results from a simulation study of Carlén et al. (2006), comparing a linear and a threshold model. Therefore, in this study only linear models were used.

Several studies have shown that udder health traits in different parities are genetically different traits, although correlations are highly positive (e.g., Carlén et al., 2004). The number of traits analyzed in this study was large (17 traits) and this would have been increased with parity-specific trait definitions. Potential traits for a selection index were selected after this study. Therefore, inclusion of a fixed parity effect and a random permanent animal effect in the model was considered to be sufficient to correct for parity differences in this study.

The bacteriology trait CS had a heritability and average incidence similar to $\mathrm{CM}$ in the data sets described in De Haas et al. (2008), and had high genetic correlations with traits derived from SCC (Table 7). These correlations were somewhat greater than those between CM recorded by farmers and SCC traits (De Haas et al., 2008). Genetic correlation between CS and ISCM was moderate and similar to the estimates of the correlation of CM and ISCM in their study.

\section{Genetic Correlations of CS and Other Mastitis Traits}

The genetic correlations estimated between CS/CM and ISCM in different data sets showed that CS is potentially useful as a CM indicator and is different from ISCM. The genetic correlations between CS and $\mathrm{CM}$ were high and similar to the correlation of $\mathrm{CM}$ in the data sets A and B of De Haas et al. (2008), even though the definition of CS was clearly different from that of CM in the other 2 data sets and the majority of the bacteriology samples was visually normal. Because ISCM was genetically the same trait in all 3 data sets (and also defined and calculated equally), it was expected that genetic correlations of this trait with CS and CM would be nearly equal for the different combinations of traits. However, the figures in Table 8 suggested that these correlations were not identical and varied between 0.49 and 0.74 . The standard errors were relatively large, too, and the estimates were not significantly different from the estimates of genetic correlations between the CM and SCM traits within each data set. Confirmation with trivariate analyses was attempted, but most runs did not converge. Because the data sets used were relatively small, and the bivariate correlation estimates had considerable standard errors, more research is needed.

\section{Usefulness of Bacteriology Data for Estimation of Udder Health Breeding Values}

Disease records are not necessarily required for genetic improvement of udder health because indirect traits are available that can be used for breeding value estimation, but adding information on disease occurrence can improve the reliability of breeding values (Heringstad et al., 2000; Mark et al., 2002). Disease records of a portion of the population are also relevant for monitoring purposes (Shook, 1989) and can be used to obtain genetic correlations between breeding goal and index traits. This study indicated that bacteriology data can be used as an alternative for disease recording. Farms that submitted samples for bacteriology were compa- 
rable with average Dutch herds and yielded unbiased information. An advantage of the use of bacteriology data is that an on-going collection of bacteriology data in a central database already exists in the Netherlands, but disease recording for CM does not.

The Dutch breeding goal for udder health consists of CM and SCM. Addition of traits derived from bacteriology data to the selection index is useful if they improve the reliability of breeding values. The trait CS had stronger genetic correlations with the SCC traits used in this study than CM recorded by farmers as reported by De Haas et al. (2008). This implies that CS will provide less additional information than CM recorded by farmers when it is included in a selection index, but determination of the optimal selection index from the 17 traits analyzed in this study is subject of a separate study.

\section{CONCLUSIONS}

Information from the 2 distinct flows of bacteriology samples in the Netherlands could be combined into one trait for genetic analysis. The amount of udder health information that could be obtained this way, however, was limited because many farmers did not take samples for bacteriology. Farmers that took samples reported, on average, greater milk production and lower SCC than farmers that did not, but variation within both groups of farms was similar. Additionally, there was a large overlap in sires used within both groups. Whether or not samples were taken for bacteriology, they turned out to be potentially useful as an indicator of CM. This trait had a high positive genetic correlation with $\mathrm{CM}$ registered by farmers, had similar genetic variation, and also had heritabilities and genetic correlations with SCC traits similar to CM registered by farmers. Therefore, data from sampling for bacteriology can be used for genetic improvement of udder health. An important advantage compared with direct registration of $\mathrm{CM}$ is that data are already collected routinely and stored in a central database.

\section{ACKNOWLEDGMENTS}

The GD Animal Health Service (GD) is acknowledged for providing data from bacteriological culturing. This study is part of the 5-year mastitis program of the Dutch Udder Health Center (UGCN) and was financially supported by the Dutch Dairy Board (PZ). The authors thank Otlis Sampimon for fruitful discussions and help with interpretation of the data set.

\section{REFERENCES}

Calus, M. P. L., J. J. Windig, and R. F. Veerkamp. 2005. Associations among descriptors of herd management and phenotypic and genetic levels of health and fertility. J. Dairy Sci. 88:2178-2189.
Carlén, E., U. Emanuelson, and E. Strandberg. 2006. Genetic evaluation of mastitis in dairy cattle using linear models, threshold models and survival analysis: A simulation study. J. Dairy Sci. 89:4049-4057.

Carlén, E., E. Strandberg, and A. Roth. 2004. Genetic parameters for clinical mastitis, somatic cell score, and production in the first three lactations of Swedish Holstein cows. J. Dairy Sci. 87:30623070 .

De Haas, Y., W. Ouweltjes, J. ten Napel, J. J. Windig, and G. de Jong. 2008. Alternative somatic cell count traits as mastitis indicators for genetic selection. J. Dairy Sci. 91:2501-2511.

De Haas, Y., Y. H. Schukken, H. W. Barkema, and R. F. Veerkamp. 2003. Genetic associations for pathogen-specific clinical mastitis and somatic cell count patterns. Anim. Sci. 77:187-195.

De Jong, G., and L. Lansbergen. 1996. Udder health index: Selection for mastitis resistance. Interbull Bull. 12:42-47.

Djabri, B., N. Bareille, F. Beaudeau, and H. Seegers. 2002. Quarter milk somatic cell count in infected dairy cows: A meta-analysis. Vet. Res. 33:335-357.

Gilmour, A. R., B. J. Gogel, B. R. Cullis and R. Thompson. 2006. ASReml User Guide Release 2.0. VSN International Ltd., Hemel Hempstead, UK.

Heringstad, B., G. Klemetsdal, and J. Ruane. 2000. Selection for mastitis resistance in dairy cattle: A review with focus on the situation in the Nordic countries. Livest. Prod. Sci. 64:95-106.

Hogan, J. S., R. N. Gonzalez, R. J. Harmon, S. C. Nickerson, S. P. Oliver, J. W. Pankey, and K. L. Smith. 1999. Laboratory Handbook on Bovine Mastitis. Rev. ed. National Mastitis Council, Madison, WI.

Koivula, M., A. Pitkälä, S. Pyörälä, and E. A. Mäntysaari. 2007. Distribution of bacteria and seasonal and regional effects in a new database for mastitis pathogens in Finland. Acta Agric. Scand. A 57:89-96.

Mark, T., W. F. Fikse, U. Emanuelson, and J. Philipsson. 2002. International genetic evaluations of Holstein sires for milk somatic cell and clinical mastitis. J. Dairy Sci. 85:2384-2392.

NMC. 2008. Recommended mastitis control program, international version, http://nmconline.org/docs/NMCchecklistInt.pdf Accessed May 6, 2008.

NRS. 2005. Manual NRS, Chapter E-18, pp. 1-9, http://www.nrs.nl/ cms/servlet/dbupload?id=3537 Accessed January 29, 2008.

Olde Riekerink, R. G. M., H. W. Barkema, D. F. Kelton, and D. T. Scholl. 2008. Incidence rate of clinical mastitis on Canadian dairy farms. J. Dairy Sci. 91:1366-1377.

Schukken, Y. H., T. J. G. M. Lam, and H. W. Barkema. 1997. Biological basis for selection on udder health traits. Interbull Bull. 15:27-33.

Schukken, Y. H., D. J. Wilson, F. Welcome, L. Garrison-Tikofsky, and R. N. Gonzales. 2003. Monitoring udder health and milk quality using somatic cell counts. Vet. Res. 34:579-596.

Sears, P. M., B. S. Smith, P. B. English, P. S. Herer, and R. N. Gonzalez. 1990. Shedding pattern of Staphylococcus aureus from bovine intramammary infections. J. Dairy Sci. 73:2785-2789.

Shook, G. E. 1989. Selection for disease resistance. J. Dairy Sci. 72:1349-1362

Sol, J., O. C. Sampimon, E. Hartman, and H. W. Barkema. 2002. Effect of preculture freezing and incubation on bacteriological isolation from subclinical mastitis samples. Vet. Microbiol. 85:241-249.

Van den Borne, B. H. P., G. Van Schaik, G. De Jong, and T. J. G. M. Lam. 2006. Determination of a definition of subclinical mastitis incidence based on somatic cell counts in the Netherlands. Pages 609-611 in Proc. of 11th Int. Symp. Veterinary Epidemiology and Economics, Cairns, Australia.

Van Werven, T., E. N. Noordhuizen-Stassen, A. J. J. M. Daemen, Y. H. Schukken, A. Brand, and C. Burvenich. 1997. Preinfection in vitro chemotaxis, phagocytosis, oxidative burst, and expression of $\mathrm{CD} 11 / \mathrm{CD} 18$ receptors and their predictive capacity on the outcome of mastitis induced in dairy cows with Escherichia coli. J. Dairy Sci. 80:67-74. 